\title{
Hybrid ESP Courses as Tool to Improve Students' Informal Learning and Educators' Academic Mobility
}

\author{
Eva Minasyan ${ }^{1 *}$, Armine Grigoryan ${ }^{2}$, and Yulia Kuznetsova ${ }^{3}$ \\ ${ }^{1}$ Department of Foreign Languages №1, Plekhanov Russian University of Economics, 117997, 36 Stremyannyi per., Moscow, \\ Russia \\ ${ }^{2}$ Department of Foreign Languages №2, Plekhanov Russian University of Economics, 117997, 36 Stremyannyi per., Moscow, \\ Russia \\ ${ }^{3}$ Department of Foreign Languages №3, Plekhanov Russian University of Economics, 117997, 36 Stremyannyi per., Moscow, \\ Russia
}

\begin{abstract}
The era of advanced information and communication technologies is offering new opportunities and challenges for the integration of web-based authentic materials into the learning settings. Such teaching elements are regarded British Council LearnEnglish, BBC English, Ted-Ed, YouTube Edu, LearnOutLoud, LinguaLeo communicating and collaborating tools, which are integrated in course development to create blended learning context for ESP (English for Specific Purposes) auditorium. The article suggests strategies for implementing British Council LearnEnglish.org, BBC English, Ted-Ed, LearnOutLoud, LinguaLeo materials in order to foster learners' awareness and cooperation in hybrid courses. The analyses of British Council LearnEnglish.org, BBC 6-minute English, Ted-Ed, LearnOutLoud, LinguaLeo online platforms illustrate the benefits and peculiarities of language learning process by using virtual sources.
\end{abstract}

\section{Introduction}

Currently the higher education undergoes tremendous changes and reformation dictated by the requirements of international academic society and huge influence of elearning technologies on the entire educational process. The integration of these technologies plays a key role to form contemporary educational models which promote knowledge acquisition and skills development through lifelong learning and personal development.

It is worth mentioning that Russian higher educational system faces unpredicted challenges and opportunities caused by these changes which are vital and inevitable to enter the global academic community. As A.V. Sobol and T.I. Krasnova state, 'the flexibility of education with a student-centered approach has become a leading idea now' [1]. Moreover, web-enhanced learning and student-oriented methods of teaching are recognized as modernized ways to increase the quality of language learning and meet the challenges of decreased face-to-face learning hours, expanded auditoriums, multilevel and multicultural groups. Educators, who combine today the roles of instructors, mentors, consultants and tutors, are forced to experiment various innovative models of teaching by implementing information and communication technologies. It is obvious that the integration of online learning resources parallel to traditional modes is beneficial for both educators and learners as they increase the learners' autonomy, make courses interesting and creative and create great potential for enhancing web-based teaching and learning environment. Hybrid courses lead to improvement of students' informal learning and educators' academic mobility. 'Partial effects from measures of prior academic achievement upon performance in the blended version were significantly different from partial effects provided by the same measures in the traditional version of the course' prove C. J. Asarta and J. R. Schmidt in their recent study [2].

\section{Methods and Materials}

At present blended learning has become a catchphrase in educational environment meaning the academic context where traditional and e-learning models are intertwined. $\mathrm{K}$. Thorne states 'Blended learning is the most logical and natural evolution of our learning agenda' [3]. Hence online resources play a supportive, supplementary role alongside with face-to-face contact hours. As in many countries, so in our case in Russia blended learning is gaining its decent position in higher education sphere supporting the initiatives to integrate technology in course curriculum, 'to facilitate learning, teaching and research by providing ICT tools and making it easy to access digital learning resources' [4].

It is supposed and proven by many researchers that blended learning creates the best context for providing learners with balanced proportion of traditional study and online support leading to student self-study and

* Corresponding author: Minasyan.ET@ rea.ru 
higher level engagement. 'The objective of blended learning and of the use of online resources is to stimulate self-learning so that the sessions are used for discussion and problem solving' argue Ana M.B. Pavani and W. S. Barbosa [5].

Recently the majority of scholars have carried on qualitative and quantitative analyses related to synergistic effects of hybrid courses, and amongst them A. F. Alshehri's study on 'Student satisfaction and commitment towards a blended learning finance course' [7], E. K. Prokhorets, M. V. Plekhanova and N. G. Scherbinina's research suggesting 'Instructional Design of Foreign Language Blended Courses' [8] and H. M. Vo, Ch. Zhu and N. A. Diep, who analyze 'The effect of blended learning on student performance at course-level in higher education' are noteworthy [9].

To keep pace with international educational reforms and innovative matrix curriculum designs, Plekhanov Russian University of Economics is greatly emphasizing the need to supplement class contact time with online resources and 'provide enhanced opportunities to supporting a wide diversity of students' needs' [10].

Blended learning courses are usually created by integration of diverse online academic platforms, like Moodle, TED.com, UDACITY, Coursera, KnowledgeNet, iHomework, Creative Commons, 2U, Open Culture, YouTube videos, etc. which suggest quite engaging online tutorials, effective and accessible for self-study in informal settings. While designing our matrix curriculum for undergraduate economists we have supplemented each unit with online topic-relevant audiovideo materials from British Council LearnEnglish.org, BBC 6-minute English, Ted-Ed, LearnOutLoud, LinguaLeo. The mentioned e-learning resources offer flexible and wide-range videos with pre- and postwatching tasks stimulating learner, listening activities which improve not only audio skills, but as well as build vocabulary and enhance intercultural competence, improve teacher interaction and close collaboration. Educators can create activities, which target diverse language skills, and share with learners who may study outside class hours 'at any convenient time there by increasing education efficiency' [11].

\section{Discussion}

\subsection{Blended learning context supplemented by online sources}

A primary focus of the following web resources is to provide high-quality lessons taught by exceptional educators. British Council LearnEnglish.org, BBC 6minute English, Ted-Ed, LearnOutLoud, LinguaLeo encompass the following useful elements applicable for foreign language teaching regardless the specialization and language level:

Listening \& Vocabulary: Long-running series of topical discussion and new vocabulary are brought to learners by the favourite BBC Learning English presenters. All 6 Minute English programmes discuss diverse socio-cultural issues and give six useful items of vocabulary [12].

Audio \& Video Directory: LearnOutLoud.com is a huge destination for audio and video learning, where learners can browse over 50.000 educational audio books, podcasts and videos [13].

Lessons \& Series: which are built around any TEDEd original talks or YouTube videos suggesting special programs that support students in discovering, exploring and presenting their big ideas in the form of short, TEDstyle talks [14].

Nominate: The most meaningful TED-Ed videos are collaborations between the TED-Ed team and at least one of the following: a curious learner, an exceptional educator, or a talented visualization artist. Any of these people can help by guiding mutual efforts to create a library of lessons worth sharing by acting on one of the options above.

English Skills: Great language skills could help learners to get into top universities, move up the career ladder, find new friends and be confident while travelling. The British Council is offering a wide range of free opportunities to learn English and make it fun! Check out free digital learning websites for children, teenagers and grown-ups developed by the British Council jointly with the BBC, learn English with the exciting English learning apps and get useful advice and recommendations daily in Learn English website [15].

All these components make these online educational sources quite appealing and challenging not only for educators, who investigate and develop their expertise, but they can nominate and engage experts, thus widely cooperating with peers. Moreover, they share lessons with learners with the intention to encourage individual learning, increase motivation and language engagement. The roles of British Council LearnEnglish.org, BBC 6minute English, Ted-Ed, LearnOutLoud, LinguaLeo can be defined as innovative idea and knowledge collaboration, contribution, information storage and exchange used to enhance web-based learning and improve language competencies, foster learners' selfstudy skills and enrich educators' professionalism. Similarly S. Hubackova and I. Semradova claim on this point that 'learners get used to autonomous work, to the course construction and its control... to work better with separate tools of the course, their orientation in the tasks set is better. They understand better what is required from them and that is why they find the course more user-friendly' [16].

\subsection{Exceptional educational applications of virtual resources}

British Council LearnEnglish.org, BBC 6-minute English, Ted-Ed, LearnOutLoud, LinguaLeo online lessons are seen as a tool for collaboration, as the latter is an utmost life skill to achieve academic and professional success, self-development and self-realization. 'Collaboration is the main feature of future work environment and should be reflected in authentic activities thoroughly designed by educators' [17]. 


\subsubsection{TED-Ed Lessons Worth Sharing}

TED-Ed Lessons consist of activities, like Watch, Think, Dig Deeper and Discuss, which promote critical thinking, concentration and active listening, better understanding and adoption of new materials, expanding professional skills. The lessons and tasks combine such features as purposefulness, motivation, interest, integrity, participants' mutual aspiration for the common goal and interconnection, effective distribution of roles and functions (i.e. educators as creators and instructors, learners - explorers and knowledge seekers), selfdiscipline, conformity and capability to achieve the objectives. In this case collaboration through integration of web-based learning sources is helpful to acquire knowledge and skills, socialize and communicate effectively via information and communication technologies.

As TED-Ed webpage illustrates, TED-Ed Lessons are filtered by Content Type, Student Level, Video Duration and Subtitles. They cover a wide range of topics, such as the Arts, Business \& Economics, Design, Engineering \& Technology, Health, Literature \& Language, Mathematics, Philosophy \& Religion, Psychology, Science \& Technology, Social Studies, Teaching \& Education, Thinking \& Learning. The initial glace at the diversity of themes reveals the hidden importance and vitality of the talks which shade a new light on social and academic issues, provide a fresh look at global topics and innovative views to tackle the problems related to a specific sphere of study or job.

What refers to particularly Business \& Economics section, the educators' work is simplified by offering them even narrower subdivision of videos related to current economic environment and business issues. Lesson activities, created by educators of great expertise, are of various types: Multiple choice, Open and Closeend Questions, supplementary reading passages and an idea suggested for further discussion and argument development. These types of tasks encourage and foster critical and analytical thinking, problem solving, discussing and cooperating skills. Moreover, these authentic videos boost listening skills, enlarge and enrich job or study related word stock, motivate informal learning and self-development, and last but not least, they improve the learners' writing skills.

\subsection{What do LearnOutLoud audio \& video materials suggest?}

LearnOutLoud audio \& video resources demonstrate a huge number of materials grouped under some headings encompassing nearly all socio-cultural areas with related issues, like Arts \& Entertainment, Business, Education \& Professional, Languages, Politics, Science \& Technology, Religion \& Spirituality, etc. (See Fig 1. Audio \& Video, podcasts and audiobook downloads). Even the titles reveal the paramount importance and relevance of topics which make them appealing and interesting for larger auditoriums. LearnOutLoud audio \& video resources are supported with helpful reviews, comments and descriptions which lead to better comprehension, analytical thinking and knowledge gaining in an individual way.

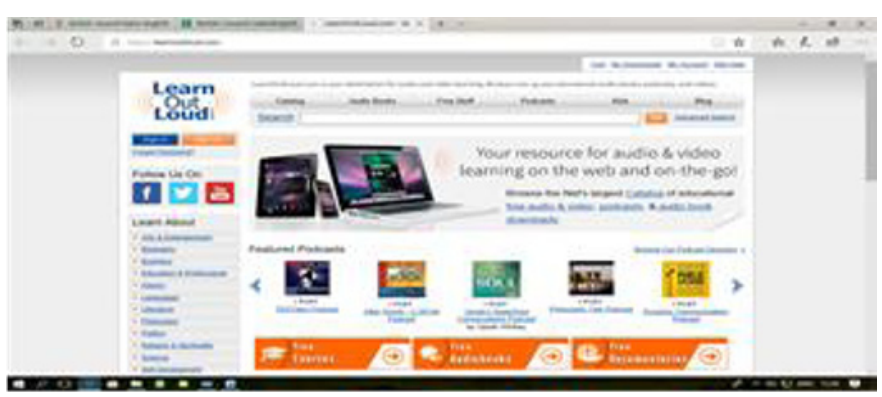

Fig.1. Audio \& Video, podcasts \& audio books.

As a way to illustrate, here is an example of a fine audio book You Can, You Will by Joel Osteen running 3 hours 40 minutes and presented in unabridged edition. The audio material is supported by Description, Reviews and Comments which are proven to be very useful for future economists, mainly entrepreneurs and managers, who would act on the global business environment.

\section{Description}

In You Can, You Will, Joel Osteen focuses on the eight irrefutable traits and attributes of highly successful people. These personal qualities are tested through the ages and all types of circumstances. These practical principles guide the lives of champions:

- Create bold visions

- Dare to dream big dreams

- Run your own race

- Focus on your unique course and goals

- Think positively

- Control your thoughts and attitudes

- Expect good things to happen

- Anticipate great opportunities

- Stay passionate

- Light the fire within and approach life with enthusiasm

- Commit to excellence

- Do your best and maintain high standards

- Keep growing

- Deal with your weaknesses and continually improve

- Serve others

- Invest yourself in others

\subsection{What does BBC Learning English offer?}

It is a platform to spark curiosity and celebrate students' ideas from around the world targeting areas from English at University to Work, from Pronunciation to Drama, etc. (See Fig. 2. BBC Learning English Tools) 


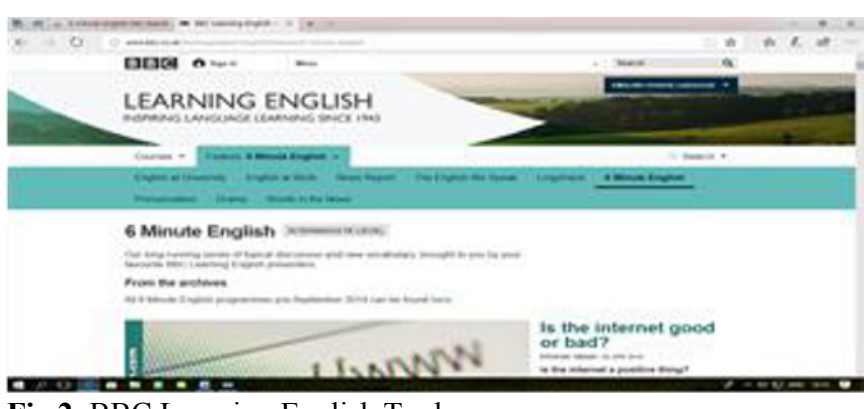

Fig.2. BBC Learning English Tools.

BBC Learning English is a flexible series of 6-minute listening activities, meant for students to discover their passions and discuss ideas either during or after school. They encompass inspiring news and audio-video series for learners, who want to learn English mostly out of formal settings. Such as:

1) Lingohack (video news stories)

2) News Report (audio news stories)

\subsection{Online resources integrated in ESP hybrid course designs}

Coming to educational applications of British Council LearnEnglish, BBC English, Ted-Ed, LearnOutLoud, LinguaLeo resources it is due to mention that they serve as a warehouse for diverse topics related to social and scientific issues. Both educators and students can share interesting videos and ideas, teachers can even customize the lessons by creating and sharing a new lesson based on that.

Another type of collaboration is the section for discussions or comments, like in TED-Ed Clubs, in BC LearnEnglish Your Comments, and in LearnOutLoud Reviews \& Discussion, where these online resources become a workshop for idea brainstorming, debating and team-working, paragraph writing, critical thinking, later developing group projects and reproducing in the style of $\mathrm{BBC}, \mathrm{TED}$ or YouTube talks. One of the key advantages in integrating above presented virtual sources is the learning environment where learners participate according to their own pace and by themselves rather than passively receive it. Learners are actively engaged in the study process, which results in effective learning outcomes. Another benefit is that these web-based lessons can be student-produced items where learners share their reflections, opinions and knowledge and develop cooperating, socializing and language skills.

Not far ago we have developed and designed ESP blended courses for undergraduate and postgraduate students in Plekhanov Russian University of Economics (PRUE). The course curriculum materials have rather flexible nature, so the learners can complete at any convenient time, yet being stuck to the deadline of task or unit submission. To guarantee successful and effective completion of the activities, students are constantly provided with precise directions and necessary help by educators.

In-company designed courses (Management Insights, English for Business Communication, English for
Professional Use, Business Correspondence, PRUE, 2017-18) contain British Council LearnEnglish.org, BBC 6-minute English, Ted-Ed, LearnOutLoud, LinguaLeo audio-video sources relevant to every unit theme. The lessons develop further the discussed topic, provide new insights into the issue and encourage critical thinking. The process of watching or listening, afterwards performing the tasks gives the learners a lot of fun and motivation. On the one hand, the webenhanced materials are challenging and innovative, on the other hand, they foster the learners' self-confidence and self-study management. The final Follow-on activities, e.g. Discuss \& Present, Reviews, Comments, are designed specifically to promote collaborative thinking and generate an argument by contemplating and sharing their ideas in groups.

\section{Results}

Educators' and students' perceptions of web-based learning

As technology is constantly evolving in more sophisticated ways, it opens new doors of opportunities for educators to supplement the teaching materials with virtual sources. Novel trends of technology-led education result in the emergence of hybrid learning where traditional teacher-led methods are merged with learner-centered ones, thus creating blended learning. This model 'has a potential to enhance the quality of teaching and learning' [18].

In case of Plekhanov Russian University of Economics, the integration of technology as a strategy is meant for engaging and motivating learners thereby enhancing informal self-study and increase educators' academic mobility. Within the scope of hybrid learning students are not only given some amount of knowledge, but they are taught different ways of thinking, develop creativity and problem solving with peer assistance or without, perform learning in formal and informal situations. 'E-learning technologies transform ordinary transfer of knowledge into cooperative learning, help to bring together the positions of instructors and students, activate their creative potential' [11].

So, the widespread integration of hybrid courses is evident in all academic disciplines in PRUE. Foreign language teachers were among the early adopters who started using blended learning method to design course curriculum and increase students' engagement and outcome. Students access learning materials and assignments from any convenient place and at any convenient time. British Council LearnEnglish, BBC 6minute English, Ted-Ed, YouTube Edu, LearnOutLoud, LinguaLeo audiovisual materials are easy to use and cover a wide range of themes with challenging tasks that make the process of language learning entertaining end effective, still offering intensive continuous practice. Considering from learners' perspective, they get easily excited about the potential of blended learning and continually push the boundaries of learning further and further opening new opportunities to recognize talent, 
expand the space of personal development with world class capacity.

Nowadays the educator's role in further or higher education is a mixture of the following titles: mentor, trainer, coach, facilitator, developer, learning designer, educator and consultant [19]. In order to combine all these roles in one successfully they are deeply 'interested in creating learning solutions that reflect and capitalize on the full breadth of learning opportunities' [3]. Thus, educators benefit greatly from the implementation of virtual learning materials in institutional courses as they give them larger space for innovation and creativity. The curriculum supplemented with web-based resources looks rather progressive and productive as it encompasses all language skills and meets diverse language needs. Hereby, the educator acts as a course moderator leading the learner to a virtual environment where group collaboration and self-engagement are of core importance.

\section{Conclusion}

The overall results of integrating British Council LearnEnglish, BBC 6-minute English, Ted-Ed, YouTube Edu, LearnOutLoud, LinguaLeo audiovisual resources in ESP curriculum in PRUE are encouraging and effective. Both educators and learners see these online learning materials as valuable collaborative tools. When the podcasts, videos and listening tracks with Follow-on discussion activities are incorporated in blended learning context the learners' motivation has increased and their potential for learning developed. The collaborative environment that online resources facilitate can teach students 'how to cooperate and work together, how to create a community, and how to operate in the world where the creation of knowledge and information is becoming a group effort' suggests W. Richardson [20].

In the context of hybrid courses, the online materials provide a vast space for educators and learners to explore the audio-visual units in informal settings, in their own way and develop their language skills and profession related knowledge through mainly self-study. Educators, lesson creators and blended course designers search the web-based language learning sources, in our case British Council LearnEnglish, BBC 6-minute English, Ted-Ed, YouTube Edu, LearnOutLoud, LinguaLeo materials in an asynchronous way, on their own, and spend vast amount of time for exploring, selecting and supplementing the study materials with them. Later learners are provided with detailed instructions and guidance to perform the tasks, thus improving language skills both in face-to-face and informal learning settings. This model of blended learning is based mainly on student-centered approach and self-study techniques, which lead the students to life-long learning and ease the process of further professional development.
1. A.V. Sobol, T.I. Krasnova, Social and Behavioral Sciences, 29-33, (2015)

2. C. J. Asarta, J. R. Schmidt, The Internet and Higher Education 32, 29-38, (2017)

3. K. Throne, Blended learning: how to integrate online and traditional learning (Kogan Page Limited, London, 2003)

4. J. MacDonald, Blended learning and online tutoring: Planning learner support and activity design, (Gower Publishing, Ltd, 2008)

5. Ana M.B. Pavani, W. S. Barbosa, IFACPapersOnLine 49(6), 198-202 (2016)

6. A. F. Alshehri, Research in International Business and Finance 41, 423-433 (2017)

7. E. K. Prokhorets, M. V. Plekhanova, N. G. Scherbinina, Procedia - Social and Behavioral Sciences 215, 161-169 (2015)

8. H. M. Vo, Ch. Zhu, N. A. Diep, Studies in Educational Evaluation 53, 17-28 (2017)

9. M. Asoodar, S. S. Marandi, M. R. Atai, Sh. Vaezi, Computers in Human Behavior 41, 533-543 (2014)

10. European Commission / EACEA / Eurycide. Modernisation of Higher Education in Europe: Access, Retention and Employability, Eurydice Report (Publications Office of the European Union, Luxemburg, 2014)

11. I.S. Vanjushin, T.I. Krasnov, Social and Behavioral Sciences, 34-38 (2015)

12. BBC Learning English, (URL: http://www.bbc.co.uk/learningenglish/, Retrieved 27.04.2018)

13. Learn Out Loud, (URL: https://learnoutloud.com/, Retrieved 27.04.2018)

14. Lessons Worth Sharing -Ted-Ed Talks, (URL: https://ed.ted.com/, Retrieved: 27.04.2018)

15. British Council LearnEnglish, (URL: http://learnenglish.britishcouncil.org/en/, Retrieved 27.04.2018)

16. S. Hubackova, I. Semradova, Procedia - Social and Behavioral Sciences 217, 551-557 ( 2016)

17. M. Muscarà, S. Beercock, Procedia - Social and Behavioral Sciences 2(2), 2885-2889 (2010)

18. Y. Park, Ji Hyun Yu, Il-Hyun Jo, The Internet and Higher Education 29 (2016)

19. E.T. Minasyan, Pedagogy and education 1, 87-90, (2018)

20. W. Richardson, Blogs, wikis, podcasts and other powerful web tools for classrooms (Corvin, 2010)

\section{References}

